\title{
Collection, curation and the use of humidification to restore nest shape in a research museum bird nest collection
}

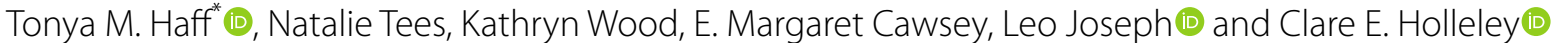

\begin{abstract}
Background: Bird nests are an important part of avian ecology. They are a powerful tool for studying not only the birds that built them, but a wide array of topics ranging from parasitology, urbanisation and climate change to evolution. Despite this, bird nests tend to be underrepresented in natural history collections, a problem that should be redressed through renewed focus by collecting institutions.

Methods: Here we outline the history and current best practice collection and curatorial methods for the nest collection of the Australian National Wildlife Collection (ANWC). We also describe an experiment conducted on nests in the ANWC using ultrasonic humidification to restore the shape of nests damaged by inappropriate storage.

Results: The experiment showed that damaged nests can be successfully reshaped to close to their original dimensions. Indeed, restored nests were significantly closer to their original shape than they were prior to restoration. Thus, even nests damaged by years of neglect may be fully incorporated into active research collections. Best practice techniques include extensive note taking and photography in the field, subsampling of nests that cannot or should not be collected, appropriate field storage, metadata management, and prompt treatment upon arrival at the collection facility.

Conclusions: Renewed focus on nest collections should include appropriate care and restoration of current collections, as well as expansion to redress past underrepresentation. This could include collaboration with researchers studying or monitoring avian nesting ecology, and nest collection after use in bird species that rebuild anew each nesting attempt. Modern expansion of museum nest collections will allow researchers and natural history collections to fully realise the scientific potential of these complex and beautiful specimens.
\end{abstract}

Keywords: Best practice, Bird, Curation, Nest, Nest shape, Natural history collection, Humidification, Object restoration, Preservation

\section{Background}

Bird nests are an integral component of avian ecology. The beauty and diversity of their form and placement have intrigued naturalists since antiquity (Darwin 1871; Brewer 1878; Wallace 1889; Aristotle c. 350 BC). Within recent times, avian phylogenetics has enabled a focus

*Correspondence: Tonya.Haff@csiro.au

Australian National Wildlife Collection, National Research Collections

Australia, CSIRO, GPO Box 1700, Canberra, ACT 2601, Australia on the evolution of general characteristics of bird nests (Sheldon and Winkler 1999; Zyskowski and Prum 1999; Irestedt et al. 2006; Drury and Burroughs 2016; Price and Griffith 2017; Englert Duursma et al. 2018; Fang et al. 2018; Medina 2019; Mouton and Martin 2019; Nagy et al. 2019). Typically, ecological studies of nests are based on descriptions from field observations (Deeming and Reynolds 2015).

Generalised nest characteristics are important for informing macroecological studies, but far more 
information can be acquired from detailed physical inspection of nest voucher specimens. Nests are intentionally created objects, built of diverse materials, both natural and artificial. Nests also create an environment for ectoparasites, fungal growth, bacterial communities, nest commensals, and brood parasites. They are thus rich sources of biological data: a single nest is a habitat, an environmental sample, an indicator of breeding status, a record of species-specific behaviour, the stage for inter-species interactions, and an example of animal architecture (Hansell 2000, 2007; Goodfellow 2011). Consequently, nests are powerful tools for the study of topics as varied as animal behaviour, entomology, parasitology, plant ecology, urbanisation, and climate change. For example, study of trace-DNA left behind in bird nests has been used to identify the cryptic species that occupied them (Arnold et al. 2017). Similar techniques could provide a new source of species occurrence data to improve biodiversity assessment. Study of physical nests also has revealed the selective use of construction material for specific functions, including camouflage through optical illusion, tensile strength, sanitation, regulation of egg evapotranspiration, and response to climatic conditions (Ar and Rahn 1980; Freymann 2008; Aubrecht et al. 2013; Ruiz-Castellano et al. 2016, 2018; Campbell et al. 2018). Collected nests may also be used to describe contemporary and historical species range limits for birds, insects and plants (Rulik and Kallweit 2006; Russell et al. 2013).
All of these facets of nest research depend on collections housed in museums. Indeed, use of nest specimens should represent a baseline standard, because voucher specimens enable species verification, study repeatability, and the testing of future hypotheses (Remsen 1995; Suarez and Tsutsui 2004; Clemann et al. 2014; Rocha et al. 2014; Schmitt et al. 2018). Yet despite the high research potential of nests, they have typically been underrepresented in collections, and consequently underutilized (e.g., Wiedenfeld 1982; ANWC collection, below; Green and Scharlemann 2003). For example, a hummingbird nest collected in Brazil by Joseph Banks and Daniel Solander in 1768 had the note 'scientific value-nil' added to its museum label around the turn of the twentieth century (Allen 2003). A similar bias is evident in an historical text on how to collect and preserve bird eggs and nests (Bendire 1891). It devoted seven pages to egg collecting alone, but a single paragraph on the collection, preservation, and curation of nests. Compounding the problem, nests of species such as corvids and raptors are large, unwieldy and difficult or impossible to collect in their entirety, are difficult to store (Fig. 1a). Consequently, nest collections tend to be small and taxonomically biased compared to egg and skin collections (Aguilera Román and Wiley 2012).
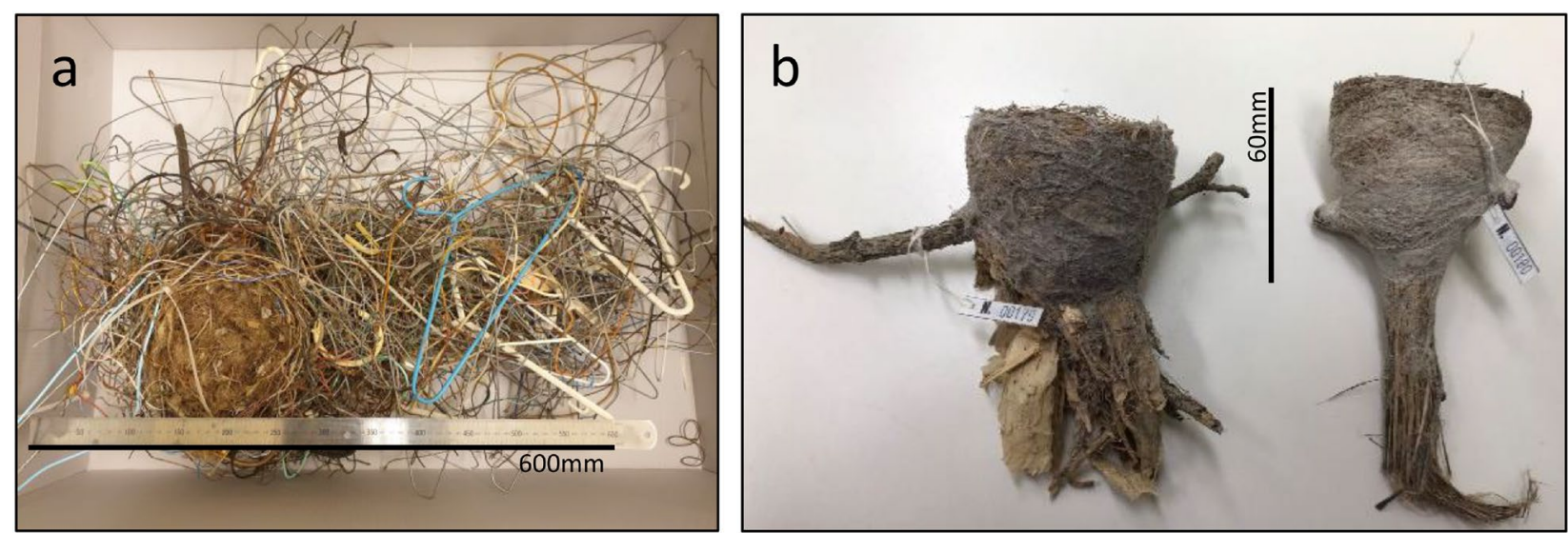

Fig. 1 Nest shape and structure affects storage and management. a An Australian Magpie (Gymnorhina tibicen) nest ANWC N00252, composed almost entirely of human-made material, including clothes hangers and cables. Large and unwieldy nests such as this are difficult to collect and store. b Two Grey Fantail (Rhipidura albiscapa) nests ANWC N00179 and N00180, demonstrating ways that registration tags may be affixed to nests. At the ANWC the preferred method is to tie the registration tag on to the nest site attachment (left). If there is no appropriate nest site attachment, tags may be tied through the nest side wall, using spacer knots to avoid tension on the nest structure (right). This can be useful in that it allows researchers to examine the tag with minimal movement of nest materials but is only appropriate when nest structure is sufficiently robust 
The historical neglect of nests as collection items may be redressed by a renewed focus on nest collection, the application of modern research techniques, and appropriate curation. Accordingly, we describe the collection, curatorial history and current management protocols of the Australian National Wildlife Collection's nest collection. The collection is relatively small but biogeographically and phylogenetically important, particularly in light of the now well-established Australian origins of songbirds (Moyle et al. 2016; Oliveros et al. 2019). We also present the results of a humidification experiment to restore the three-dimensional shape of songbird nests damaged by crowded storage conditions. The information in this paper represents a comprehensive compilation of best-practice standards for the curation of nests and their metadata, and the collection management protocols to ensure the security, growth and long-term utility of museum nest collections.

\section{Methods}

\section{The Australian National Wildlife Collection nest collection}

The Australian National Wildlife Collection (ANWC) is a research-only collection of approximately 200,000 specimens of Australasian terrestrial vertebrates. It is housed by the Australian Commonwealth Government's scientific research organisation, the CSIRO, in Canberra, Australia. The collection began by aggregating the individual collections of CSIRO researchers conducting ecological studies in the 1950s and 60s. Consequently, the collection is data-rich though relatively young. Since the 1980s, most specimens are also associated with a cryogenically stored tissue sample appropriate for genetic research.

The ANWC currently houses approximately 800 individual bird nests, the majority of which have detailed ecological data, and often associated accessioned egg clutches. Almost all nests in the collection are from Papua New Guinea or Australia. Nest collection efforts were most intensive during bird and mammal surveys of Papua New Guinea in the 1960s and 70s. Field collection strategically targeted songbird nests from species whose nests were either scientifically undescribed or were accompanying voucher specimens of nesting birds. These nests were not photographed, but were richly documented with notes on substrate, contents, and dimensions. In addition to New Guinean nests, the ANWC collection consists of several hundred nests collected in the Australian Capital Territory and in the Northern Territory, Australia in the 1970s and 1980s. More recently, the ANWC has acquired the historical nest and egg collections of several Australian private egg collectors, including Robert Green, Mervin T.
Goddard, John Kershaw, and Donald Seton (Mason and Pfitzner 2020). The ANWC collection is heavily biased towards the nests of passerines (at the time of writing $93 \%$ of registered nests are of passerines, and 7\% from five other orders).

Although earlier ANWC staff collected nests, they prioritised the preparation and curation of other kinds of specimens that required more immediate attention, such as eggs and whole birds. When staff did collect nests, they brought them back to the ANWC and put them into storage to await accession and curation. Consequently, some nests were disfigured due to years of substandard storage and compression in bags and boxes of low archival quality, and most were not databased. ANWC staff began to prioritise nest curation around 2016. Nest curation and databasing are now ongoing and active projects at the ANWC.

\section{Best practice nest collection and curation protocols}

The ANWC does not currently collect active nests, and has not done so in approximately 30 years. Critically, any ANWC collecting followed and follows all local and federal regulations and permitting processes for collecting nests. In Australia, nests of all native species are protected, but specific state or territory legislation determines whether and when inactive nests may be collected. At the ANWC no collecting of any kind of specimen is conducted without first obtaining appropriate animal ethics permits, as well as appropriate state and territory salvage and scientific collecting permits.

Current protocols for collecting nests at the ANWC focuses, with appropriate permits, on donated nests from historical collections and on recently inactive nests of species that build new nests for each breeding attempt. These nests are data-rich, yet their collection poses fewer, if any, ethical considerations than the collection of active nests. Collecting recently inactive nests has always been done in conjunction with direct observation of the parents and nest contents. This increases the utility of nest data and the certainty of identification and taxonomic assignment. Ideally, nests should be collected as soon as possible after they are no longer used by adult birds. Care must be taken when monitoring the nest to not influence the outcome of the nest by accidentally alerting predators to nest location, or by harassing parents into abandoning the nest (Ralph et al. 1993). When the nest is ready to be collected, current protocol dictates that it is first described and photographed in situ. The entire nest should then be removed, including the attachment sites when possible, photographed again, and accompanied by detailed notes on nest dimensions, composition 
and structure, all of which are digitally linked to the nest record (for excellent examples of detailed metadata collection for nests see Simon and Pacheco 2005; Gonzaga et al. 2016).

Nest structure and dimensions can affect nest collectability. If a nest is too large or flimsy to be collected, our protocol dictates collecting nest lining along with some outer contents. Similarly, our protocol excludes collecting nest hollows or other nests that may be reused between breeding attempts or seasons, and instead calls for collecting subsamples of nest lining and other materials from inside cavities when the nest is not active. As with whole nests, ANWC policy calls for documentation of nest subsamples with detailed notes and photos, which are digitally linked to the permanent nest record.

After collection and documentation, or upon donation of historical collections, nests are registered and affixed with a registration tag. Affixing registration tags requires some discretion, and must be done with a minimum of damage, if any, to the nest structure (Fig. 1b). Current ANWC policy calls for the use of cardboard boxes in the field to avoid shape distortion during transport (see Humidification Experiment, below). We discourage placing nests, even temporarily, in plastic containers, because of the risk of mould growth on nests while in field storage or transit. We also avoid stuffing material such as tissue inside nests, which can distort nest shape or damage the inner nest lining. Nests collected and stored as outlined above can then be safely and easily transported back to the preparation laboratory.

Once in the preparation laboratory, nests are readied for final storage in the vaults. We air-dry all nests on indoor shelving in this space for several weeks. This helps avoid mould growth due to residual moisture. When nests are thoroughly dry, we place them in individual archival cardboard boxes, cushioned on top of archival tissue paper. Archival tissue below nests ensures that any material that falls from nests is not lost. Such debris may be used for future genetic analyses, thus avoiding the need for destructive sampling from the nest itself. Archival tissue supporting nests in the box also helps prevent movement and subsequent damage to nests, and helps to mitigate any fluctuations in humidity or residual nest dampness.

Although the external structure of many nests is resistant to pest attack, incorporated animal material, such as feathers or feather sheath fragments, is susceptible to damage by museum pests. We mitigate this risk and prevent potential introduction of pests into the vaults from nests by prophylactically treating them for pests prior to long-term storage in vaults. We fumigate nests with aluminium phosphide tablets that release phosphine gas, a non-residual fumigant with no known long-term toxicity effects, and which is also used in grain storage (WHO 1988; NIOSH 2011; ILO 2017). Phosphine fumigation avoids potential DNA degradation caused by freeze-thaw cycles (Shao et al. 2012; Soniat 2019). Further, although phosphine is highly toxic to live animals, it does not affect the cell structure of dead or dormant organisms (Nath et al. 2011), and is consequently unlikely to degrade the DNA of museum specimens.

We employ strict health, safety and environment (HSE) procedures required to avoid staff exposure to dangerous volatile chemicals. All fumigation occurs in a locked, externally vented fumigation room. Access is restricted to trained personnel, who use appropriate personal protective equipment (PPE) including closed-toe shoes, lab coat, a respirator suitable for volatile organic compounds, and goggles. Fumigated nests are ventilated using an extraction fan for 6-24 h prior to staff entering the fumigation room to remove specimens.

Prior to final storage in the vaults, we affix nest boxes with thermally printed adhesive labels. Once nests are labelled, their metadata are uploaded in batches from our database and are publicly available via the Atlas of Living Australia (http://www.ala.org.au).

\section{Nest shape restoration by humidification}

Despite the protocol that the ANWC now uses for nest collection and curation, our history has led to some nests becoming misshapen over time (see above). In addition to being unsuitable for morphometric research, crushed or misshapen nests can be difficult to sample for trace DNA without inflicting further damage. One potential solution to this problem is to reshape nests with the aid of a humidification chamber. Humidity is widely used to shape and reshape plant- and animal-based materials across a range of applications, including leather shoe making and the restoration of historical objects (Redwood 1969; Clark 1984; Morrison 1986; Alper 1993; Wills 2000; Lewis 2005; Cruikshank and Saiz 2009; Jackson and Andrew 2009; Rowe et al. 2018). Humidity is also used by collection managers and conservators to relax and reshape misshapen natural history objects made of natural materials, such as study skins (NHColl listserv, April 2020), although to the best of our knowledge this is an idiosyncratic technique that is not well documented in published literature. We judged that the risk of damage to humidifying misshapen nests should be minimal, as they are constructed primarily of natural materials and are often exposed to high levels of 
moisture and humidity while active. We subsequently trialled an experimental procedure using an in-house built ultrasonic humidification chamber, in an attempt to permanently reshape 11 nests crushed or damaged by inappropriate long-term storage. If this procedure was successful, then we planned to implement it on any nests crushed or disfigured to a state where their internal contents would be difficult or impossible to sample without further damage.

We tested humidification as a tool for nest restoration using 11 cup- or dome-shaped nests. The nests were collected in the early 1970s from Papua New Guinea and had been stored compressed together in plastic bags placed in boxes in the ANWC vaults until 2019 . One nest (ANWC N00303), with only species metadata, was used for preliminary optimisation of humidification techniques. The other ten nests had metadata that included nest dimensions at the time of collection, which allowed us to assess the efficacy of our restoration to their original shape. All nests were made by small passerines (Table 1). The basic nest metadata can be found through the Atlas of Living Australia at https://bioca che.ala.org.au/occurrences/search?q=qid\%3A15984169 38349 .

We constructed an ultrasonic humidification chamber using readily available, archival materials. The chamber was a 90 L, high-density polyethylene (HDPE) Sistema storage tub, with an upturned HDPE plastic lab tray placed inside as a table for the nests to sit upon (Fig. 2). We inserted a low-density polyethylene (LDPE) plastic tube into the output of a Beurer LB37 cool mist ultrasonic humidifier and connected it to the tub through a snug hole cut into the lid with a Dremel tool. The mist entering the chamber was not allowed to directly hit nests placed inside. Humidity was measured with a suspended Fischer hair hygrometer placed inside the chamber. The dial faced outward so that it could be read when the humidification chamber was in operation (Fig. 2). We used tap water in the humidifier. Ideally, demineralised water would have been preferable to avoid sediment build-up in the humidifier following long-term use. The chamber reached $100 \%$ humidity within 3-4 min when the chamber lid was left closed and the humidifier turned on to an output level of $150 \mathrm{~mL} / \mathrm{h}$. Once the chamber reached $100 \%$ humidity it maintained that level for over $5 \mathrm{~h}$, even after the humidifier was turned off. No water damage to the test nest was sustained when trialling these conditions.

Immediately before humidification we measured nest dimensions, so that they could be compared with dimensions after treatment. Specifically, we recorded nest diameter, in two measurements at right angles to each other across the opening or top of the nest to the outer edges of the nest, which could be combined to calculate approximate nest opening area. We also recorded nest depth, from the top of the nest structure to the bottom of the nest. These measurements were chosen because they were also recorded in the field at the time of collection, allowing for comparison to the nest dimensions before compression. All measurements are recorded in the ANWC collection management database and are available to researchers in perpetuity.

The humidification procedure we used for all nests was as follows: (1) nests were placed on the upside down lab tray in the humidification chamber; (2) the chamber lid was shut, and the humidifier turned on at an output level of $150 \mathrm{~mL} / \mathrm{h}$ for $3-4 \mathrm{~min}$, which is approximately

Table 1 ANWC nests used in humidification experiment

\begin{tabular}{llll}
\hline Species & $\begin{array}{l}\text { ANWC registration } \\
\text { number }\end{array}$ & Nest type & Nest materials \\
\hline Melanocharis longicauda & N00325 & Dome & Moss, plant fibre, fern hairs \\
Melidectes belfordi & N00324 & Cup & Plant fibre, grass, stems, green moss, fern hairs \\
Microptilotis albonotata & N00334 & Cup & Fine grasses, moss, animal hair, cobwebs, seed plumes \\
Microptilotis orientalis & N00304 & Cup & Fine stems, cobwebs, moss, leaflets, seed down \\
Pachycephala soror & N00290 & Cup & Rootlets, fine tendrils, ferns, leafy liverworts \\
Pycnopygius cinereus & N00323 & Cup & Coarse grasses, leaves, cobweb, lichen, fine grass \\
Pycnopygius cinereus & N00333 & Leaves, fibres, rootlets, fine grass stems \\
Rhipidura cockerelli & N00303 & Cup & Fine grass, cobwebs \\
Symposiachrus axillaris & N00315 & Cup & Fern stems, fine rootlets, green moss \\
Symposiachrus guttula & N00299 & Cup & Green fern fibres, fern rootlets \\
Toxorhamphus poliopterus & Algae, cobwebs, cocoons, plant down
\end{tabular}




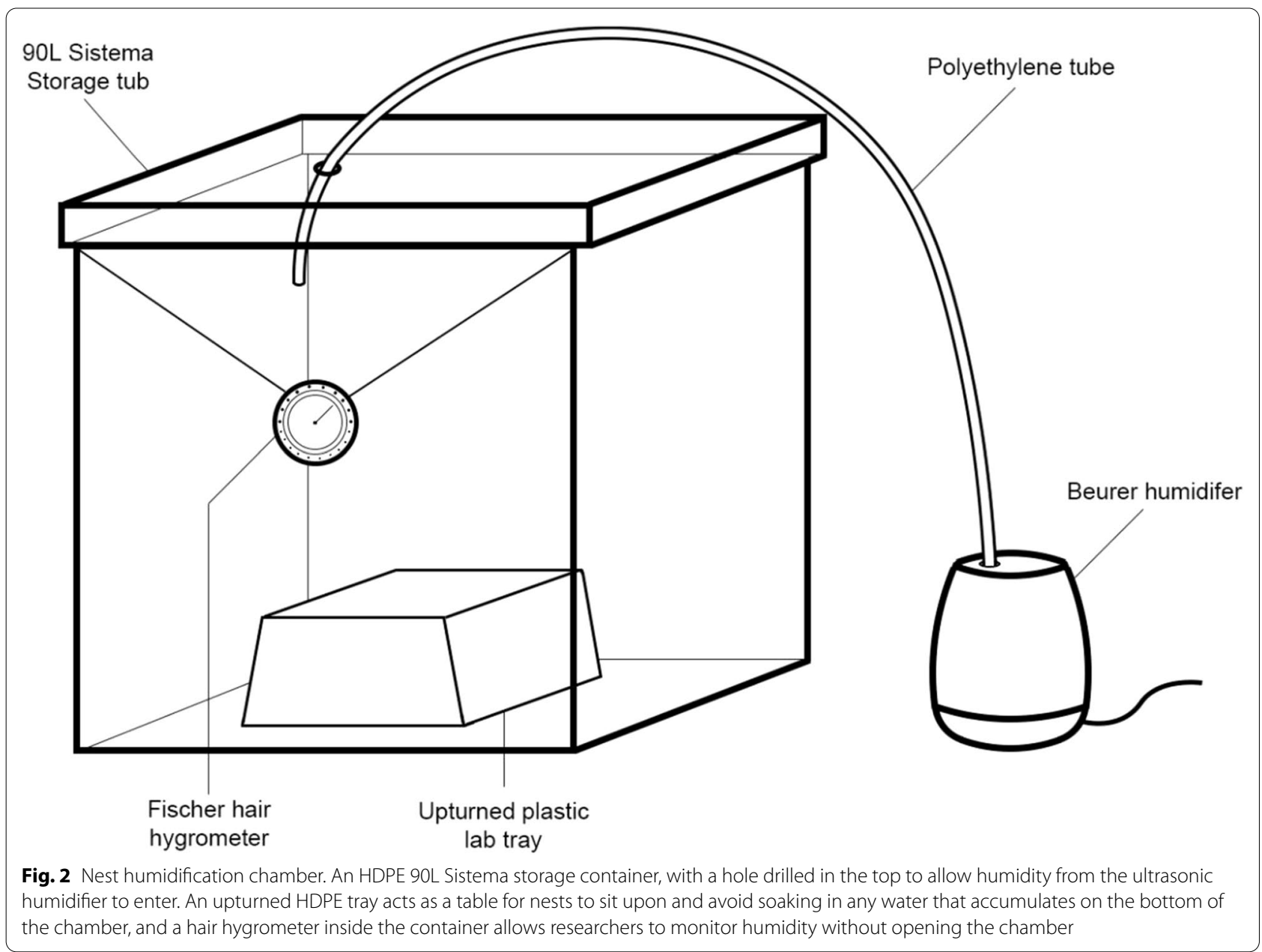

how long it took the chamber to reach $100 \%$ humidity (above); (3) once the hygrometer indicated 100\% humidity the humidifier was left to run for $10 \mathrm{~min}$, and then switched off to prevent oversaturation and excess condensation in the chamber; (4) the nests were checked every $30 \mathrm{~min}$, and removed when they were judged to be malleable enough to be reshaped ( $\min 1 \mathrm{~h}$, max $2.5 \mathrm{~h}$, median $1.5 \mathrm{~h}$ ). Briefly (approximately $5 \mathrm{~s}$ ) opening the lid to check nests did not affect the humidity of the chamber.

Once softened by humidity, we nests were gently manipulated nets by hand and then pinned in place on foam boards. We attempted to shape the nests to recreate the original nest dimensions recorded in the field at the time of collection. For dome-shaped nests $(n=1)$ and for nests that were difficult to pin without potential damage $(n=1)$, we inserted tissue paper into the nest cup to stabilise its shape. We left nests pinned in position for 10-14 days to "set" the nest in the restored shape (e.g., Alper 1993). We then removed the pins and, when used, tissue paper, and let nests sit for an additional week. This ensured that they were completely dry and allowed enough time to determine if the treatment was successful, or if the nests reverted to the "memory" of their compressed shape. At the end of the entire treatment we re-recorded the dimensions of each dry nest.

We used several measures to judge the success of nest restoration. Because of the small sample size in this study and the qualitative nature of the restoration (e.g., whether or not nests "looked" better), visual measures of success are probably sufficient to demonstrate that the technique can be successful, and we therefore present before-andafter photos of the nests. We also include graphical representation of their original, compressed, and restored measurements to illustrate the success of humidification in nest restoration. We tested for quantitative differences 
between original and restored nest shape and examined whether restored nests were more similar to their original dimensions than they had been before undergoing humidification treatment, using paired $t$ tests. All $p$ values are two-tailed, with significance determined at $p<0.05$. Analysis was conducted using $\mathrm{R}$ and GraphPad (Prism 2015; Wickham 2016). Although this analysis included multiple measures of nest shape, we chose not to apply correction methods such as Bonferroni procedures because they make interpretation of results less clear, increase the chance of type II errors, reduce statistical power, and contribute to publication bias (Nakagawa 2004). Instead, we present results so that readers can independently and directly assess test results, and stress that because of the small sample size statistical results should be interpreted together with graphical presentations of the results.

\section{Results}

Treatment in the humidification chamber was successful in relaxing nests to the point where their shape could be manipulated. Nests came out of the chamber feeling softer than when they went in, and damp. Treatment time in the chamber ranged from 1 to $2.5 \mathrm{~h}(\bar{x}=1.68 \mathrm{~h} \pm 0.46$ standard deviation, SD), and overall nests made of finer materials such as grass and cobwebs needed less time in the chamber than nests comprised of sturdier materials such as twigs (soft material, $n=7, \bar{x}=1.43 \mathrm{~h} \pm 0.35 \mathrm{SD}$ compared to sturdy material, $n=4, \bar{x}=2.13 \mathrm{~h} \pm 0.25$ $\mathrm{SD})$.

Humidification allowed us to reshape compressed nests. Visually, nests looked rounder and more upright after restoration, and graphical display of nest measurements demonstrates that the shape of most nests changed to be more similar to their original dimensions after treatment, even though we were not able to restore them to the exact dimensions as before compression (Figs. 3, 4). Restored nest dimensions were significantly smaller than their original dimensions in the field (mean original nest area $84.33 \mathrm{~cm}^{2} \pm 11.63$ standard error of the mean $(\mathrm{SEM})$ vs restored area $68.98 \mathrm{~cm}^{2} \pm 10.30$ SEM; $p=0.0008, t=4.95, \mathrm{df}=9$; mean original nest depth $8.65 \mathrm{~cm} \pm 0.73$ SEM vs restored depth $7.45 \mathrm{~cm} \pm 0.57$ SEM; $p=0.003, t=4.00, \mathrm{df}=9$; Fig. 5). However, the anterior surface area of restored nests was significantly more similar to their original dimensions than to anterior surface area after years of compression (mean difference between restored and original nests $-15.35 \mathrm{~cm}^{2} \pm 3.11$ SEM vs between restored and compressed nests -140.78 $\mathrm{cm}^{2} \pm 21.10$ SEM; paired $t$ test $p=0.0002 ; t=5.90, \mathrm{df}=$ 9; Fig. 4). Nest depth varied less than nest area before and after poor storage, and was more difficult to restore (mean difference between restored and original nest depth $-1.2 \mathrm{~cm} \pm 0.30 \mathrm{SEM}$ vs between restored and compressed nest depth $0.55 \mathrm{~cm} \pm 0.60$ SEM; $p=0.03$, $t=2.45$, df $=9$; Fig. 4)

\section{Discussion}

The key finding from our study was that nests disfigured by years of substandard storage can be reshaped using humidification. Restored nests did not match their original dimensions once thoroughly dried, but they were more naturally shaped than they were before treatment. The improvement was visually striking. Further, treated nests were more similar to their original dimensions than they were before treatment. Overall, we suggest that humidification has great potential in restoring disfigured nests. Further refinement of this technique could lead to even closer alignment of restored nests with their original dimensions. We believe that the methods outlined here show that even damaged nests can be successfully reshaped, increasing both their aesthetic appeal and their utility in an active research collection.

Several factors may have contributed to differences between the original dimensions of nests and their restored shapes. Potentially, the physical "memory" of nest materials, which were held compressed for years, may have been too strong to completely overcome (Alper 1993). Indeed, nests did seem to change shape somewhat as they dried, which is why most nests did not ultimately restore to their original shapes despite 


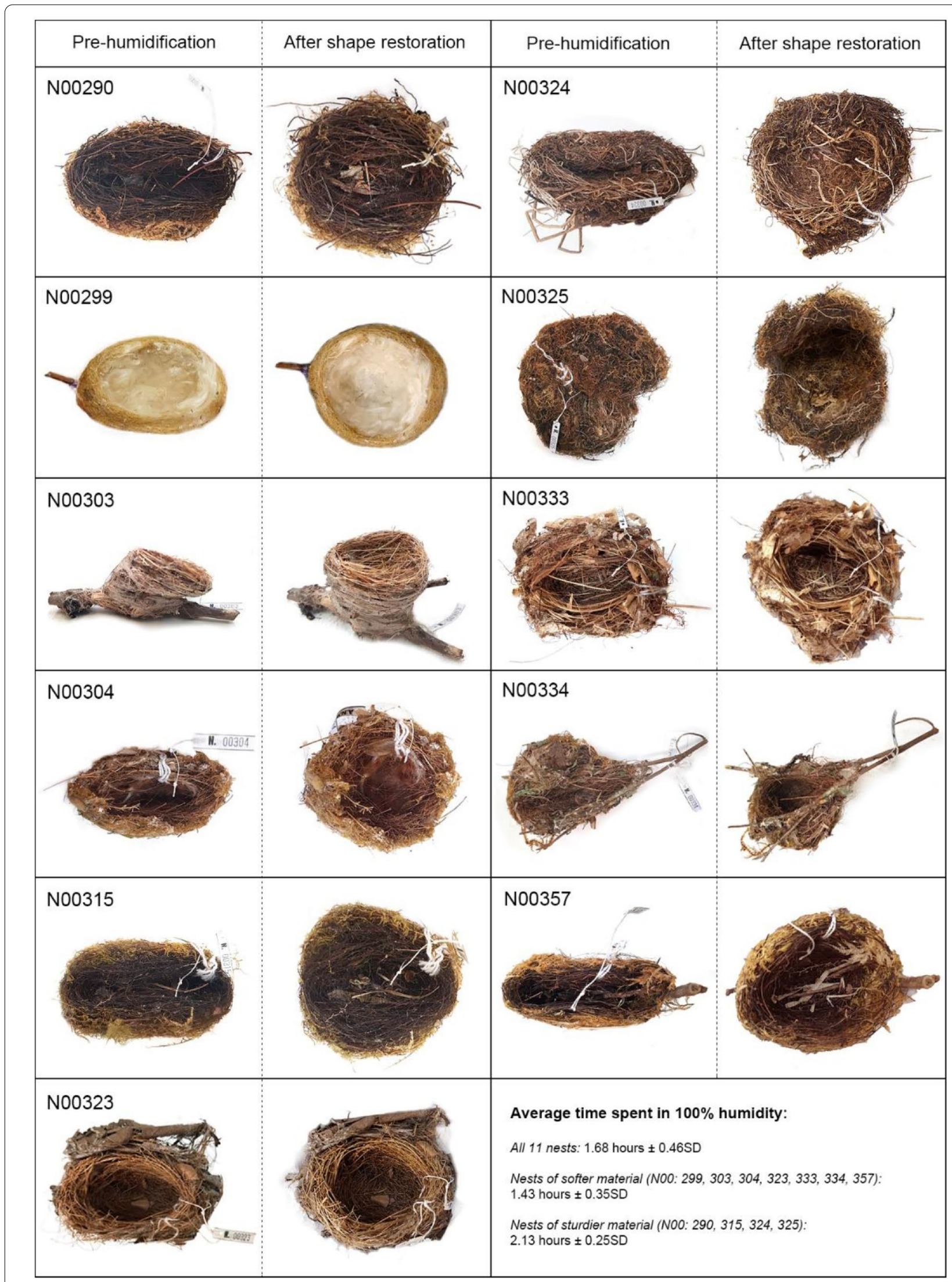

Fig. 3 (See legend on previous page.) 
being pinned to those dimensions. The length of time nests are compressed may also directly affect shape "memory", such that nests stored inappropriately for years may be harder to restore than nests disfigured for only weeks or months. Such possibilities require further investigation. Alternatively, nests may simply have required repeat or longer exposure to humidity to thoroughly dampen the interior of their substrates before pinning (Alper 1993). One future option might be to humidify nests, pin them to their original dimensions on a small foam board, and then humidify the nests again, or at multiple stages, before drying completely, to help erase past shape memory. Any future trials would be complimented by daily monitoring of nest dimensions for several weeks after humidification, to better understand the timing and dynamics of nest shape change during the drying period.

We reshaped nests based on exterior diameter and depth measurements, the only measurements taken in the field at the time of collection. However, other aspects of nest structure, such as nest wall thickness and internal cup dimensions, can also affect overall nest shape, and have measurable effects on nest function (Heenan and Seymour 2011, 2012). Consequently, collecting data on a wide range of interior and exterior nest dimensions in the field at the time of collection is critical going forward, both to capture data that may be important for future research and to assist in future restoration requirements. Future reshaping trials based on a wider range of original nest measurements, varying lengths of time in suboptimal storage, experimentation in the length of time left pinned after drying, and with a larger sample size with more statistical power, will be important in fully understanding the full potential of this method.

Renewed attention to nest restoration and curation should be matched with growth of nest collections. This will help realise the full scientific potential of these complex and beautiful specimens. Nest voucher specimens and the data derived from them may prove increasingly prescient for topics such as climate change or epidemiology (Cook et al. 2020) and the evolution of nest-building itself (Price and Griffiths 2017). Further, given the care necessary not to impact reproductive or social behaviour, expansion of nest collections is effectively another method of sampling bird species for their genetic material. This adds to vertebrate collections with fewer ethical concerns than methods involving humanely killing live animals. For example, museum staff could collaborate with researchers at universities and other institutions who are involved with monitoring or studying nesting birds (e.g., Ralph et al. 1993), so that the nests are collected or subsampled and donated at the end of the attempt or breeding season. Nests so obtained could be of utmost value because they would be associated with a wealth of behavioural and ecological data (Arnold et al. 2017).

\section{Conclusions}

Overall, there are positive signs that nests are starting to receive more and renewed attention by researchers and museum staff for description and museum collection (Simon and Pacheco 2005; Russell et al. 2013; Gonzaga et al. 2016). There is still much about bird

\section{(See figure on next page.)}

Fig. 4 Line plots of nest area $\left(\mathrm{cm}^{2}\right)$ and depth $(\mathrm{cm})$ before compression ("original"), after compression ("compressed"), and after restoration ("restored"). Note that while nests were not restored to their original dimensions, their restored shape tended to be more similar to their original shape than before restoration. Also note that nest area is a rough estimate of nest shape, and changes in nest area may not represent true nest shape (e.g., nest N00323). ${ }^{*}$ Nest N00303 = trial nest without original measurement data 


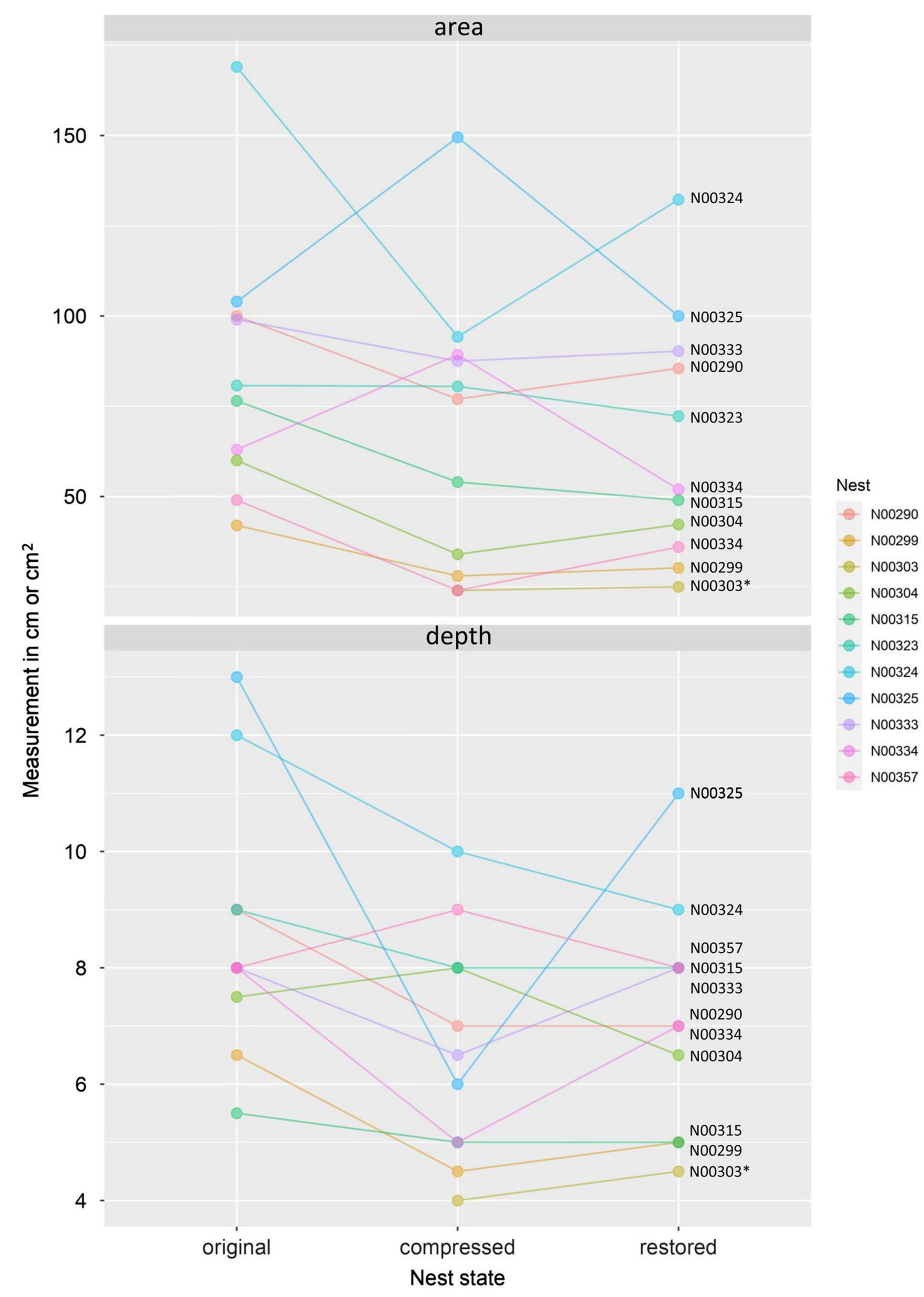

Fig. 4 (See legend on previous page.) 


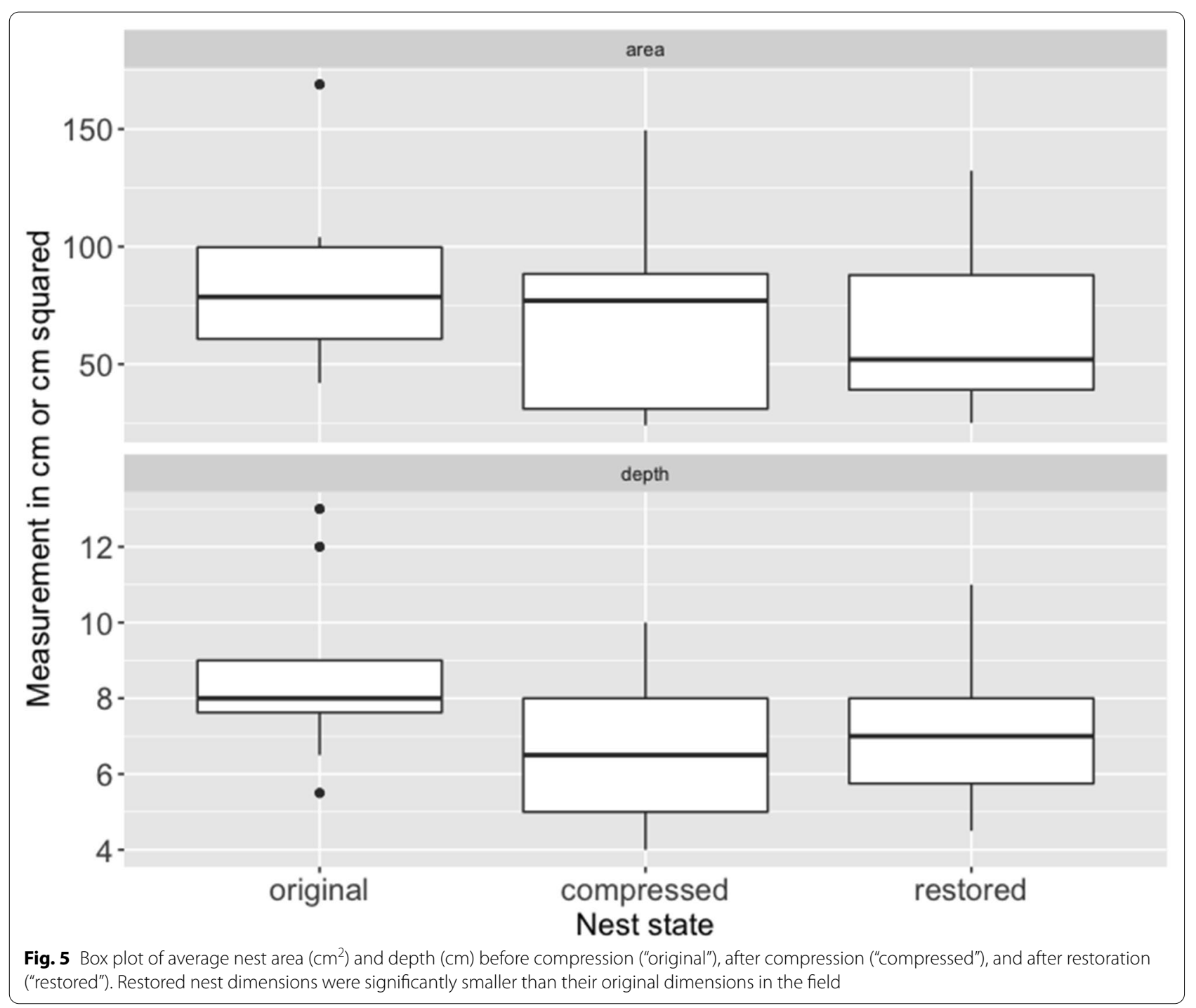

nests and nest ecology to be discovered and understood. Studying nest voucher specimens will provide an important avenue to such understanding. This is particularly so now, as rapid changes in technological capabilities for studying nests intersect with mounting anthropogenic changes in the world. Future work in curating, growing, and diversifying existing nest collections using low-impact methodologies will ensure the utility and centrality of nests to museum collections for generations to come.

\section{Acknowledgements}

Many thanks to the contributions and assistance of lan Mason, Dick Schodde, Andrew Young and Rob Lanfear.

\section{Authors' contributions}

TH wrote the manuscript, designed and supervised the humidification project, and analysed the data. NT conducted the humidification experiment, contributed to the manuscript content and created the figures. KW contributed to the manuscript content and contributed photos to Fig. 1. MC provided help with intern oversight, nest metadata, and contributed to the manuscript. LJ provided guidance and manuscript feedback and editorial advice. $\mathrm{CH}$ sought funding, founded internship program, provided project oversight, contributed to the manuscript and provided manuscript feedback and editorial advice. All authors read and approved the final manuscript.

\section{Funding}

Funding for this project was provided by the CSIRO National Research Collections Australia Strategic Funding and the Australian National Wildlife Collection Curatorial Internship Program.

\section{Availability of data and materials}

The datasets used and/or analysed during the current study are available from the corresponding author on reasonable request.

\section{Declarations}

Ethics approval and consent to participate Not applicable. 


\section{Consent for publication}

Not applicable.

\section{Competing interests}

The authors declare that they have no competing interests.

Received: 10 December 2020 Accepted: 3 June 2021

Published online: 24 June 2021

\section{References}

Aquilera Román R, Wiley JW. Bird egg and nest specimens in the collection of the Instituto de Ecología y Sistemática, La Habana. Cuba J Carib Ornithol. 2012;25:15-23.

Allen DE. A hummingbird nest from James Cook's Endeavour voyage, 1768-1771. Arch Nat Hist. 2003;30:163-5.

Alper D. How to flatten folded or rolled paper documents. National Park Service Conserve O Gram. 1993;13:1-4.

$\operatorname{Ar} \mathrm{A}, \mathrm{Rahn} \mathrm{H}$. Water in the avian egg: overall budget of incubation. Amer Zool. 1980;20:373-84

Arnold AE, Andersen EM, Taylor MJ, Steidl RJ. Using cytochrome $b$ to identify nests and museum specimens of cryptic songbirds. Conserv Genet Resour. 2017:9:451-8.

Aubrecht G, Huber W, Weissenhofer A. Coincidence or benefit? The use of Marasmius (horse-hair fungus) filaments in bird nests. Avian Biol Res. 2013;6:26-30.

Bendire C. Directions for collecting, preparing, and preserving birds' eggs and nests. Bull U S Natl Mus. 1891;Part D:3-10.

Brewer TM. Variations in the nests of the same species of birds. Am Nat. 1878:12:35-40

Campbell BL, Hurley LL, Griffith SC. Behavioural plasticity under a changing climate; how an experimental local climate affects the nest construction of the zebra finch Taeniopygia guttata. J Avian Biol. 2018;49:e01717.

Clark T. Conservation of an Aboriginal wallaby skin water bag at the Australian museum. In: Fogle S, editor. Recent advances in leather conservation. Proceedings of a refresher course. Washington: The Foundation of the American Institute for Conservation; 1984.

Clemann N, Rowe KMC, Rowe KC, Raadik T, Gomon M, Menkhorst P, et al. Value and impacts of collecting vertebrate voucher specimens, with guidelines for ethical collection. Mem Mus Victoria. 2014;72:141-51.

Cook JA, Arai S, Armién B, Bates J, Carrion Bonilla CA, de Souza Cortez MB, et al. Integrating biodiversity infrastructure into pathogen discovery and mitigation of emerging infectious diseases. Bioscience. 2020;70:531-4.

Cruikshank P, Saiz GV. An early gut parka from the Arctic, its past and current treatment. Prepared for the ICON-ethno workshop scraping gut and plucking feathers: the deterioration and conservation of feather and gut materials. York: University of York; 2009.

Darwin C. The descent of man, and selection in relation to sex. London: John Murray; 1871

Deeming DC, Reynolds SJ. Nests, eggs, and incubation: new ideas about avian reproduction. Oxford: Oxford University Press; 2015.

Drury JP, Burroughs N. Nest shape explains variation in sexual dichromatism in New World blackbirds. J Avian Biol. 2016:47:312-20.

Englert Duursma D, Gallagher RV, Price JJ, Griffith SC. Variation in avian egg shape and nest structure is explained by climatic conditions. Sci Rep. 2018:8:4141.

Fang Y-T, Tuanmu M-N, Hung C-M. Asynchronous evolution of interdependent nest characters across the avian phylogeny. Nat Commun. 2018:9:1863.

Hansell M. Bird nests and construction behaviour. Cambridge: Cambridge University Press; 2000

Hansell M. Built by animals: the natural history of animal architecture. Cambridge: Cambridge University Press; 2007.

Freymann BP. Physical properties of fungal rhizomorphs of marasmioid basidiomycetes used as nesting material by birds. Ibis. 2008;150:395-9.

Goodfellow P. Avian architecture: how birds design, engineer and build. Princeton: Princeton University Press; 2011.
Gonzaga LP, Ozanick C, de Piacentini VQ, Carvalho CE. First description of the nest and notes on parental care of Oustalet's Tyrannulet, Phylloscartes oustaleti (Passeriformes: Tyrannidae). Rev Bras Ornitol. 2016;24:349-53.

Green RE, Scharlemann JPW. Egg and skin collections as a resource for longterm ecological studies. Bull BOC. 2003;123A:165-76.

Heenan CB, Seymour RS. Structural support, not insulation, is the primary driver for avian cup-shaped nest design. Proc R Soc B. 2011:278:2924-9.

Heenan CB, Seymour RS. The effect of wind on the rate of heat loss from avian cup-shaped nests. PLoS ONE. 2012;7:e32252.

International Labour Organization (ILO). Phosphine: International Chemical Safety Card 0694. Geneva: World Health Organisation; 2017.

Irestedt M, Fjeldså J, Ericson PGP. Evolution of the ovenbird-woodcreeper assemblage (Aves: Furnariidae)_major shifts in nest architecture and adaptive radiation. J Avian Biol. 2006:37:260-72.

Jackson K, Andrew H. Gut reaction: the history, treatment and isplay techniques of gut garments at the Pitt Rivers Museum. Prepared for the ICON-ethno workshop scraping gut and plucking feathers: the deterioration and conservation of feather and gut materials. York: University of York; 2009.

Lewis R. Interpretation in conservation: a rare leather find from an early historic crannog. Conservator. 2005;29:87-94.

Mason IJ, Pfitzner GH. Passions in ornithology: a century of Australian egg collectors. Canberra: Andrew Isles Natural History Book; 2020.

Medina I. The role of the environment in the evolution of nest shape in Australian passerines. Sci Rep. 2019;9:5560.

Morrison L. The conservation of seal gut parkas. Conservator 1986;10:17-24

Mouton JC, Martin TE. Nest structure affects auditory and visual detectability, but not predation risk, in a tropical songbird community. Funct Ecol. 2019;33:1973-81.

Moyle RG, Oliveros CH, Andersen MJ, Hosner PA, Benz BW, Manthey JD, et al. Tectonic collision and uplift of Wallacea triggered the global songbird radiation. Nat Commun. 2016;7:12709.

Nagy J, Hauber ME, Hartley IR, Mainwaring MC. Correlated evolution of nest and egg charcateristics in birds. Anim Behav. 2019:158:211-25.

Nakagawa S. A farewell to Bonferroni: the problems of low statistical power and publication bias. Behav Ecol. 2004;15:1044-5.

Nath NS, Bhattacharya I, Tuck AG, Schlipalius DI, Ebert PR. Mechanisms of phosphine toxicity. J Toxicol. 2011;2011:494168.

Oliveros CH, Field DJ, Ksepka DT, Barker FK, Aleixo A, Andersen MJ, et al. Earth history and the passerine superradiation. P Natl Acad Sci USA. 2019:116:7916-25.

Price JJ, Griffith SC. Open cup nests evolved from roofed nests in the early passerines. P Roy Soc London B Bio. 2017;284:20162708.

Prism G. version 6.04 for Windows. California: GraphPad Software; 2015

Ralph CJ, Geupel G, Pyle P, Martin TE, DeSante DF. Handbook of field methods for monitoring landbirds. Albany: Pacific Southwest Resaerch Station; 1993.

Redwood M. The demands made on leather by new processes for the manufacture of footwear and other goods. Soc Leather Trades Chem J. 1969;73:266-72.

Remsen JV. The importance of continued collecting of bird specimens to ornithology and bird conservation. Bird Conserv Int. 1995;5:145-80.

Rowe S, Ravaioli F, Tully C, Narvey M. Conservation and analysis on a shoestring: displaying gut parkas at the Polar Museum, Cambridge. J Conserv Mus Stud. 2018;16:1-11.

Ruiz-Castellano C, Tomás G, Ruiz-Rodríguez M, Soler JJ. Nest material preferences by spotless starlings. Behav Ecol. 2018;29:137-44.

Ruiz-Castellano C, Tomás G, Ruiz-Rodríguez M, Martín-Gálvez D, Soler JJ. Nest material shapes eggs bacterial environment. PLoS ONE. 2016;11:e0148894.

Rulik B, Kallweit U. A blackbird's nest as breeding substrate for insects—first record of Docosia fumosa Edwards, 1925 (Diptera: Mycetophilidae) from Germany. Studia Dipterologica. 2006:13:41-3.

Russell DGD, Hansell M, Reilly M. Bird nests in museum collections: a rich resource for research. Avian Biol Res. 2013:6:178-82. 
Schmitt CJ, Cook JA, Zamudio KR, Edwards SV. Museum specimens of terrestrial vertebrates are sensitive indicators of environmental change in the Anthropocene. P Roy Soc London B Bio. 2018;374:20170387.

Shao W, Khin S, Kopp WC. Characterization of effect of repeated freeze and thaw cycles on the stability of genomic DNA using pulsed field gel electrophoresis. Biopreserv Biobank. 2012;10:4-11.

Sheldon FH, Winkler DW. Nest Architecture and Avian Systematics. Auk. 1999;116:875-7.

Rocha LA, Aleixo A, Allen G, Almeda F, Baldwin CC, Barclay MVL, et al. Specimen collection: an essential tool. Science. 2014;344:814-5.

Simon JE, Pacheco S. On the standardization of nest descriptions of neotropical birds. Rev Bras Ornitol. 2005;13:143-54.

Soniat TJ. Assessing levels of DNA degradation in frozen tissues archived under various preservation conditions in a natural history collection. Lubbock: Texas Tech University; 2019.

Suarez AV, Tsutsui ND. The value of museum collections for research and society. Bioscience. 2004;54:66-74.
The National Institute for Occupational Safety and Health (NIOSH). Phosphine Atlanta: National Institute for Occupational Health and Safety: Centers for Disease Control and Prevention; 2011. https://www.cdc. gov/niosh/topics/phosphine/. Accessed 19 June 2020.

Wallace AR. Darwinism: an exposition of the theory of natural selection, with some of the applications. London: MacMillan; 1889.

Wickham H. ggplot2: elegant graphics for data analysis. New York: Springer; 2016.

Wiedenfeld DA. A nest of the Pale-billed Antpitta (Grallaria carrikeri) with comparative remarks on antpitta nests. Wilson Bull. 1982;94:580-2.

Wills B. A review of the conservation treatment of a Romano-Egyptian cuirass and helmet made from crocodile skin. Conservator. 2000;24:80-8.

World Health Organization (WHO). Phosphine and selected metal phosphides. Environmental health criteria. Geneva: WHO; 1988.

Zyskowski K, Prum RO. Phylogenetic analysis of the nest architechture of neotropical ovenbirds (Funariidae). Auk. 1999;116:891-911.
Ready to submit your research? Choose BMC and benefit from:

- fast, convenient online submission

- thorough peer review by experienced researchers in your field

- rapid publication on acceptance

- support for research data, including large and complex data types

- gold Open Access which fosters wider collaboration and increased citations

- maximum visibility for your research: over 100M website views per year

At BMC, research is always in progress.

Learn more biomedcentral.com/submissions 